\title{
The availability of teaching-pedagogical resources used for promotion of learning in teaching human anatomy
}

This article was published in the following Dove Press journal:

Advances in Medical Education and Practice

29 August 2013

Number of times this article has been viewed

José Aderval Aragão ${ }^{1,5}$

Ana Terra Fonseca-Barreto ${ }^{2}$

Ciro José Brito 1,3

Danilo Ribeiro Guerra'

José Carlos Nunes-Mota ${ }^{4}$

Francisco Prado Reis ${ }^{5}$

'Master's Degree Program in Physical Education, Universidade Federal de Sergipe (UFS), Aracaju, Sergipe, Brazil; ${ }^{2}$ School of Medicine, Universidade Federal de Sergipe (UFS), Aracaju, Sergipe, Brazil; ${ }^{3}$ Department of Physical Education, Universidade Federal de Sergipe (UFS), Aracaju, Sergipe, Brazil; ${ }^{4}$ Department of Morphology, (UFS), Aracaju, Sergipe, Brazil; ${ }^{5}$ School of Medicine, Universidade Tiradentes (UNIT),

Aracaju, Sergipe, Brazil
Correspondence: José Aderval Aragão Universidade Federal de Sergipe,

Rua Aloisio Campos, 500, Bairro Atalaia, CEP: 49035-020 - Aracaju, Sergipe, Brazil $\mathrm{Tel}+557991916767$

Email jaafelipe@infonet.com.br
Abstract: Five hundred students attending higher education institutions in northeastern Brazil responded to questionnaires about their anatomy classes; students represented a variety of different health sciences disciplines. Analysis of the responses revealed the participation of teaching assistants in a large percentage of classes and the use of teaching resources, particularly images, from conventional radiographs to magnetic resonance images. The number of classes for cadaver dissection and the number of students with access to that type of class were small. In most cases, dissection was performed according to anatomic regions or systems. Medicine and nursing students had the highest number of practical dissection classes. Most students were assessed using practical and theoretical tests. Findings revealed conditions similar to those found elsewhere. Resources should be renewed and used to improve teaching for students whose courses demand the study of human anatomy.

Keywords: educational assessments, gross anatomy, dissection, education medical undergraduate, anatomic models

\section{Introduction}

Human anatomy is essential knowledge in the education of health and biological science professionals. The structure of curricular anatomy courses, the use of resources, and the commitment of professors and students are tools to promote learning. ${ }^{1}$

Dissection is a fundamental technique for physicians and other professionals who will eventually work in the fields of health care and biology; practical classes must therefore be efficient. However, the number of hours assigned to anatomy teaching in curricula has decreased over time in health-related courses. The criteria for such decisions are not clear and often lead to the elimination of dissection practices, which may in turn compromise the quality of student preparation. ${ }^{2}$

Biasutto et $\mathrm{al}^{3}$ have analyzed the importance of anatomy teaching using dissection classes and computer resources in practical and theoretical classes. They found that learning outcomes were negatively affected whenever a resource was eliminated.

New teaching methods have been developed to make the learning of human anatomy more dynamic. Ramos et $\mathrm{al}^{4}$ called attention to the need for using participative teaching techniques, which may be a response to the memorization needs of students learning the numerous and complex anatomic structures, and which may make anatomy teaching less monotonous and uninspiring. The resources and methods used by educators to approach and transmit content may reflect positively or negatively on the teaching and learning process. Therefore, innovative methods should be developed to facilitate knowledge comprehension by students..$^{5,6}$ 
The development of sophisticated technological resources and the effects of globalization have not eliminated most of the teaching deficiencies anatomy students have been exposed to for a long time. Montes ${ }^{7}$ carefully noted the main difficulties pointed out by students taking a human anatomy course: (1) program content was inadequate for the course objectives; (2) teachers lacked technical preparation and teaching experience to adapt the course to the cognitive, social, and affective profile of students; (3) the number of teaching materials used in class (cadaver or synthetic parts) was often not enough for the total number of students; (4) teachers did not deal well with the emotional reaction of students to contact with study material (eg, cadavers); (5) the basic education of students starting their university courses was insufficient, and learning and comprehension of course concepts was therefore considered difficult; and (6) current evaluation systems complicate the assessment of students' actual learning. Reverón ${ }^{8}$ found that the academic load and evaluation are, for students, the causes of greatest concern when learning in anatomy courses.

The importance of interactions between different teaching resources used in anatomy teaching, including the presence of monitors, use of images, dissection, live models, and interdisciplinarity, has been highlighted in the literature. Our present study proposed to determine the availability of teachingpedagogical resources used in the teaching of human anatomy by looking at the responses of undergraduate students to a questionnaire about their learning experiences. Surveys were given to students who were present at the Second NorthernNortheastern Applied Anatomy Symposium.

\section{Materials and methods}

A descriptive study was conducted based on applying a questionnaire (Survey S1) on the teaching-pedagogical resources used in human anatomy classes. This questionnaire was distributed among 500 undergraduates who were present at the Second Northern-Northeastern Applied Anatomy Symposium, which took place in Maceió, in 2011; students who responded were all attending higher education institutions in five different states in northeastern Brazil. All students who were willing to answer the questionnaire signed a free and informed consent statement. The statistical analysis on the students' responses consisted of numbers and percentages.

\section{Results}

Of the 500 questionnaires handed out, 264 (52.8\%) were answered and returned, and all respondents confirmed having practical anatomy classes. A few did not answer all questionnaire items. Table 1 shows a summary of answers about the use of some teaching resources.

The participation of a teaching assistant was the most frequent resource, followed by the use of radiographs, computed tomography (CT) scans, and magnetic resonance images (MRIs). The most frequent support resource was anatomic dissection, followed by the use of interdisciplinary approaches and live models. A substantial number of students did not answer the questions about support resources. The practice of dissection seemed to be limited and not satisfactory in the population under study. Of the courses represented in the sample (medicine, nursing, speech therapy, dentistry, physiotherapy, biological sciences, biomedicine, physical education, and pharmacy), only the medicine and nursing students, which accounted for $34.1 \%$ of anatomy students, reported having practical dissection classes. Therefore, about $65.9 \%$ of the students who studied anatomy did not have anatomic dissection classes (Table 2). Moreover, of the students who reported having had dissection classes, only a few reported having performed dissections during classes. Most classes were only dissection demonstrations performed by teachers or teaching assistants. Therefore, in addition to their low frequency, most classes demanded only visual and passive observation.

The analysis of type of learning assessment revealed that most instruments were theoretical and practical tests (91\%). The number of exclusively theoretical $(3.7 \%)$ or practical $(1.1 \%)$ tests was negligible. About $4 \%$ of the students did not answer this question. A large number $(168 ; 63.6 \%)$ reported that tests were in the form of practical competitions while 56 (21.2\%) had no practical tests of any type, $9(3.4 \%)$ had a few practical tests, and $31(11.7 \%)$ did not answer this question.

Table I Teaching resources used in anatomy classes

\begin{tabular}{|c|c|c|c|c|c|}
\hline & Teaching assistants & Dissection & Images & Live models & Interdisciplinary approach \\
\hline & n (\%) & n (\%) & n (\%) & n (\%) & n (\%) \\
\hline Yes & 251 (95.1\%) & $90(34.1 \%)$ & $226(85.6 \%)$ & 91 (34.5\%) & $88(33.3 \%)$ \\
\hline No & $10(3.8 \%)$ & $160(60.6 \%)$ & $30(11.4 \%)$ & $14 \mid(53.4 \%)$ & I $58(59.9 \%)$ \\
\hline No answer & $3(1.1 \%)$ & $14(5.3 \%)$ & $8(3.0 \%)$ & $32(12.1 \%)$ & $18(6.8 \%)$ \\
\hline Total & 264 & & & & \\
\hline
\end{tabular}

Abbreviation: $n$, number of cases. 
Table 2 Dissection classes according to course

\begin{tabular}{llll}
\hline Course & $\mathbf{n}$ & Dissection & \% per course \\
\hline Medicine & 108 & 80 & 30.3 \\
Nursing & 73 & 10 & 3.8 \\
Speech therapy & 36 & 0 & - \\
Dentistry & 16 & 0 & - \\
Physiotherapy & 11 & 0 & - \\
Biomedicine & 10 & 0 & - \\
Pharmacy & 4 & 0 & - \\
Physical Education & 3 & 0 & - \\
Biological Sciences & 3 & 0 & - \\
Total & 264 & 90 & 34.1 \\
\hline
\end{tabular}

Abbreviation: $n$, number of cases.

Group composition in dissection classes, whether participative or observational, ranged from two to 25 students, and mean number of participants was 4.9 per group. The analysis of how dissections were performed revealed that the most frequent technique was by anatomic region, which accounted for over $50 \%$ of the cases. There were no great differences between analyses according to systems or body surface (Table 3).

The analysis of assessment procedures revealed that, although dissection was mandatory for $87.3 \%$ (78) of students, $72.2 \%$ (64) answered that they were not tested at the end of the activity. The weekly number of hours of dissection classes ranged from 2 to 6 hours, and mean number of hours was 4 hours per week.

\section{Discussion}

Yoshida et $\mathrm{al}^{9}$ defined teaching resources as any element used in teaching to promote learning and to stimulate student perception and attention. These resources should complement the instructor's actions and should be a key component of the learning environment. Our study found that different teaching resources were used to teach anatomy: teaching assistants, dissection, images, live models, interdisciplinary approaches, and tests in the form of competitions. Learning is assumed to be enhanced when these resources are used.

A teaching assistant participated in the practical anatomy classes of $95.1 \%$ of the students. Together with teachers, the role of assistants as facilitators of the learning process has been

Table 3 Type of dissection used in anatomy classes

\begin{tabular}{lll}
\hline Type of dissection & $\mathbf{n}$ & $\%$ \\
\hline Region & 52 & 58 \\
Systems & 18 & 20 \\
Body surface & 17 & 19 \\
No answer & 3 & 3 \\
Total & 90 & 100 \\
\hline
\end{tabular}

Abbreviation: $n$, number of cases. clearly described by Campus Neto et al, ${ }^{5}$ Aversi-Ferreira et al, ${ }^{2}$ and Havet et al. ${ }^{10}$ Their work has stressed the importance of assistants in ensuring that students are active and participative and that individual learning paces are respected, which leads to more efficient learning.

A study conducted by Bearman et $\mathrm{al}^{11}$ found that information retention varies according to the sensorial experience involved. When information is heard, a mean of $20 \%$ is retained; after visualization, retention goes up to $30 \%$. The association of hearing and visualization increases this rate to $50 \%$. The highest levels, about $70 \%$, are reached when tactile sensations are included. Therefore, multisensory stimulation may be an important and efficient process to retain the content taught by teachers. In such cases, practical classes in health-related courses are indispensable for anatomy learning. Therefore, we corroborate the conclusions made by AversiFerreira et $\mathrm{al}^{2}$ about the importance of using images and live models, as well as practicing dissection, to this type of class. For Aversi-Ferreira et al, dissection is an important tool to consolidate the modern paradigms of medical education, a teaching method to encourage critical, investigative, and integrative thinking about basic data and clinical knowledge.

Dissections are not always mandatory in human anatomy courses in most programs, and the decision to include them is made by each educational institution. Despite its recognized importance, our study found that the experience of dissection, in addition to being restricted to a limited number of anatomy students, was based on observation only and required no active participation. Our study findings confirmed that only $34 \%$ of students reported having dissection classes, and fully $20 \%$ of this group only watched.

Studies about dissection in anatomy classes have revealed that student perception was mostly positive. Few students classified it as stressing, and only some defined the experience as traumatic. ${ }^{8,12,13}$ These findings suggest that this fundamentally important practice may be neglected in the process of acquiring knowledge about anatomy.

The number of students per teacher in the study groups did not seem to pose any problem. Mean number of individuals in each group was about five. This mean number may mask reality, because there were also groups with 25 students in a class. However, teamwork is important to promote the value of interpersonal relationships and student participation in teaching and learning; according to Costa, ${ }^{14}$ teamwork adds authenticity to the experience and prepares students to act and interact in individual and collective contexts.

The most frequent method of dissection was by region. Most students reported not being assessed at the end of the 
dissection activities, which is suggestive of an important flaw in the teaching practices of the students' institutions. We believe that the lack of assessment and discussions at the end of activities may reduce motivation or increase student inhibition, in addition to compromising the performance expected after practical classes. Two of the positive results of assessment are (1) that it allows teachers to collect feedback, evaluate their teaching methods, and make the necessary adjustments; and (2) it enables students to self-evaluate and try to compensate or correct for possible deficiencies. However, according to Montes, ${ }^{7}$ current assessment patterns make it difficult for students to clearly see what knowledge they have acquired.

Studies conducted by Costa, ${ }^{14}$ Aversi-Ferreira et al, ${ }^{2}$ Drake et al, ${ }^{15}$ and Reverón ${ }^{8}$ have shown that several medical schools plan to change their curricula and reduce the number of hours for practical dissections. However, Barrovecchio et $\mathrm{al}^{16}$ found that students felt the need to increase their experience with cadaver dissection in practical classes. In our study, the mean number of class hours for dissection was 4 hours a week. Although that number is satisfactory, we believe that dissection should be evaluated and restructured based on greater attention to student performance, as most students reported only watching and not participating in dissections.

Although a large range of important tools to retain content was available for most students who participated in this study, only a few of the students had practical dissection classes using live models and an interdisciplinary approach.

The relatively large percentage of students (63.3\%) with access to learning assessments through laboratory examination competition, with pins indicating the structures to be identified in 60 seconds, was a positive finding. Almost two thirds of students reported having experience with this type of evaluation tool, which offers the student direct contact with the specimens and results in a better understanding of their form, anatomic relations and variations. Montes and Souza ${ }^{17}$ also described this type of evaluation tool.

Interdisciplinary approaches, mentioned by $33.3 \%$ of the respondents, are important for the study of anatomy because they promote the construction of a global understanding of anatomic parts, their systems, and their functions when analyzed both macro- and microscopically. According to Santos and Infante-Malachias, ${ }^{18}$ an interdisciplinary approach is characterized by the existence of an object of common interest in two different disciplines, such as in biochemistry, physiology, embryology, pharmacology, and histology. However, no evidence-based data have been collected to define whether an interdisciplinary approach is more efficient than conventional classes.

\section{Conclusion}

This study confirmed the importance of the teaching assistants during practical anatomy classes, as well as the importance of using images for such classes. The practice of anatomic dissection is infrequent and deserves greater attention from those in charge of education and the organization of courses that teach human anatomy.

The conditions of the courses and different health science disciplines represented in our sample suggested that efforts should be made to reduce differences and extend student access to interdisciplinary approaches and live models. Considering the different needs of each course and discipline, the teaching-pedagogical resources used in applied anatomy are potential tools to facilitate the construction of knowledge of anatomy.

Although the sample in this study included only those students present at the symposium and did not include students from every university of the northern and northeastern regions of Brazil, the findings reveal that there is a need to implement some of the teaching resources described in this study, along with interactions between them. A widerranging study ought to be conducted in the future. This study should involve not only students but also teachers, heads of departments, and coordinators of anatomy courses at different higher education institutions, with a goal of investigating the implementation and interaction of teaching resources in anatomy teaching and learning.

\section{Disclosure}

The authors report no conflicts of interest in this work.

\section{References}

1. Yu TC, Wilson NC, Singh PP, Lemanu DP, Hawken SJ, Hill AG. Medical students-as-teachers: a systematic review of peer-assisted teaching during medical school. Adv Med Educ Pract. 2011;2:157-172.

2. Aversi-Ferreira TA, Lopes DB, Reis SMM, et al. Practice of dissection as teaching methodology in anatomy for nursing education. Braz J Morphol Sci. 2009;26:151-157.

3. Biasutto SN, Caussa LI, Criado del Río LE. Teaching anatomy: cadavers vs computers? Ann Anat. 2006;188(2):187-190.

4. Ramos KS, Pedroso AC, Guimarães GF, Santos JCC, Lacerda PSD. A case study on teaching in morphology at the State University of Pará. XXIII Brazilian Congress of Anatomy; October 19-23, 2008; Belém do Pará, Brazil. Portuguese.

5. Campus Neto FHC, Maia NMFS, Guerra EMD. 2008. The experience of teaching human anatomy-based clinic. XXIII Brazilian Congress of Anatomy; October 19-23, 2008; Belém do Pará, Brazil. Portuguese.

6. Inuwa IM, Taranikanti V, Al-Rawahy M, Habbal O. Anatomy practical examinations: how does student performance on computerized evaluation compare with the traditional format? Anat Sci Educ. 2012; 5(1): 27-32. 
7. Montes MAA. Reflections on teaching human anatomy: tools to reflect on proposals for teaching and learning [Thesis]. Rio de Janeiro: Oswaldo Cruz Institute. Available from: http:/www.enfermaria28.com.br/ Documentos\%20Anexos/Tese\%20Dr\%20MARCO\%20AURELIO\%20 DE\%20AZAMBUJA\%20MONTES.pdf. Accessed January 1, 2012. Portuguese.

8. Reverón RR. José María Vargas (1786-1854): Reformer of Anatomical Studies in Venezuela. Clin Anat. 2013

9. Yoshida M, Filho DAM, Saito DS, Araújo JC, Fornaziero CC, Omoto MHH. LocomoShow - A tool to support the teaching of human anatomy. Available from: http://www.lbd.dcc.ufmg.br/colecoes/wim/2003/007. pdf. Accessed January 1, 2012. Portuguese.

10. Havet E, Duparc F, Peltier J, Tobenas-Dujardin AC, Fréger P. The article critique as a problem-based teaching method for medical students early in their training: a French example using anatomy. Surg Radiol Anat. 2012;34(1):81-84

11. Bearman D, Trant J, van der Starre J, Wanning T. Introduction to multimedia in museums: a report by the International Council of Museums Committee on Documentation (ICOM/CIDOC), Multimedia Working Group. The Hague : CIDOC Multimedia Working Group, 1996. Available from: http://www.emuzeum.cz/admin/clanky/files/280 introtomultimediamuseums.pdf. Accessed January 1, 2012.
12. Mc Garvey MA, Farrell T, Conroy RM, Kandiah S, Monkhouse WS. Dissection: a positive experience. Clin Anat. 2001;14(3):227-230.

13. Snelling J, Sahai A, Ellis H. Attitudes of medical and dental students to dissection. Clin Anat. 2003;16(2):165-172.

14. Costa AP. Teaching human anatomy in undergraduate courses in physical education. [Dissertação]. São Paulo: São Judas Tadeu University. 2007. Portuguese.

15. Drake RL, McBride JM, Lachman N, Pawlina W. Medical education in the anatomical sciences: the winds of change continue to blow. Anat Sci Educ. 2009;2(6):253-259.

16. Barrovecchio JC, Perez B, Bella De Paz L. Tips on teaching-learning process in Human Anatomy. Rev Chil Anat. 1998;16(2):219-224. Spanish.

17. Montes MAZ, Souza CTV. Performance of college students in nonformal educational space: integrating and motivating strategy for the development of practical activities and assistance. Alex Rev Educ Cienc Tecnol. 2008;1:63-79. Portuguese.

18. Santos S, Infante-Malachias ME. Interdisciplinary and problem solving: some questions for those who shape future science teachers. Educ Soc. 2008;29(103):557-579. Portuguese. 


\section{Supplementary materials}

\section{Survey SI}

Model for data-gathering questionnaire applied to undergraduate students in relation to the resources used in teaching human anatomy.

1. Name:

2. Institution:

3. In your anatomy course, what type of class is given?

Theory ( )

Practical ( )

Theory and Practical ()

4. Number of students commonly present at practical classes:

5()

10()

15()

20()

Other numbers?

5. Do monitors assist the practical classes?

Yes ()

No ( )

6. Are dissection classes given?

Yes ( )

No ( )

7. If so, who gives them?

Student ( )

Teacher ( )

Monitor ( )

Teacher and monitor ( )

8. If the student does a dissection, how many take part in the group?

9. How many hours per week are dedicated to dissection practice? hours/week

10. Types of dissection used in anatomy classes:

Segmental ( )

Superficial ()

Systems ( )

Others ( )

11. Are students assessed at the end of the dissection practical class?

Yes ( )

No ( )

12. Are live models used in anatomy classes?

Yes ()

No ( )

13. Are images also used in anatomy classes?

Yes ( )

No ( )

If so, what imaging method is used?

Radiography ( )

Ultrasonography ( )

Computed tomography (CT scan) ()

Magnetic resonance (MRI) ( ) 
14. What type of test is used in assessments of learning from anatomy teaching?

Theory ( )

Practical ()

Theory and practical ( )

15. Are "gymkhana" tests used for practical anatomy assessments?

Yes ()

No ( )

16. Are anatomy classes given through an interdisciplinary approach?

Yes ()

No ()

Advances in Medical Education and Practice

Dovepress

\section{Publish your work in this journal}

Advances in Medical Education and Practice is an international, peerreviewed, open access journal that aims to present and publish research on Medical Education covering medical, dental, nursing and allied healthcare professional education. The journal covers undergraduate education, postgraduate training and continuing medical education including emerging trends and innovative models linking education, research, and healthcare services. The manuscript management system is completely online and includes a very quick and fair peer-review system. Visit http://www.dovepress.com/testimonials.php to read real quotes from published authors.

Submit your manuscript here: http://www.dovepress.com/advances-in-medical-education-and-practice-journal 